\begin{tabular}{|c|c|c|}
\hline 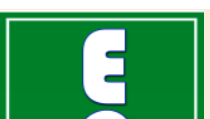 & $\begin{array}{l}\text { International Journal of Current Research in } \\
\text { Biosciences and Plant Biology }\end{array}$ & $=$ \\
\hline & Volume $7 \bullet$ Number 3 (March-2020) • ISSN: 2349-8080 (Online) & $\begin{array}{lll}\vdots & \\
\vdots \\
\vdots\end{array}$ \\
\hline $\begin{array}{l}\text { EXCELLENT } \\
\text { PUBLISHERS }\end{array}$ & Journal homepage: $\underline{w w w . i j c r b p . c o m}$ & \\
\hline
\end{tabular}

Review Article

doi: $\underline{\text { https://doi.org/10.20546/ijcrbp.2020.703.004 }}$

\title{
Health impacts of aflatoxin and control of aflatoxigenic fungi
}

\author{
Temesgen A. Gelaw ${ }^{1 *}$, Teshome G. Biru², Biniam M. Eskeziaw ${ }^{1}$ \\ and Awoke Y. Dagnaw ${ }^{1}$ \\ ${ }^{1}$ Department of Biotechnology, College of Natural and Computational Science, Debre Birhan University, \\ P.O. Box 445, Debre Birhan, Ethiopia \\ 2 Department of Applied Biology, College of Applied Natural Science, Adama Science and Technology University, \\ P.O. Box 1888, Adama, Ethiopia \\ *Corresponding author; e-mail: temesgen.assefa2129@gmail.com
}

\begin{tabular}{|c|c|}
\hline Article Info & ABSTRACT \\
\hline Date of Acceptance: & \multirow{9}{*}{$\begin{array}{l}\text { Aflatoxins are a group of related fungal metabolites primarily produced by Aspergillus } \\
\text { flavus and A. parasiticus. Aflatoxin is a global food safety concern with rural } \\
\text { subsistence farming communities in developing countries being the populations most } \\
\text { at risk of exposure. Aflatoxin contamination is the main food safety problem for field } \\
\text { crops produced in tropical and subtropical climate regions where high temperature and } \\
\text { humidity promote growth and proliferation of Aspergillus spp. Foods and feeds, } \\
\text { especially cereal grains, are susceptible to invasion by molds during pre-harvest, } \\
\text { processing, transportation, or storage. Aflatoxins impose effects in both economic and } \\
\text { health sectors where the crisis leads to death of human beings and animals. The most } \\
\text { well established health effect of chronic aflatoxin exposure are hepatocellular } \\
\text { carcinoma impaired child growth and immune suppression. To minimize the risk of } \\
\text { aflatoxicosis, there are several physical, chemical and biological methods available, but } \\
\text { the biological strategies are safest and well effective. Therefore, this review was aimed } \\
\text { to show the health impact of aflatoxins and the promising strategies against aflatoxin } \\
\text { contamination. }\end{array}$} \\
\hline o9 February 2 & \\
\hline & \\
\hline Keywords & \\
\hline Aflatoxin & \\
\hline Aspergillu & \\
\hline Bio-control & \\
\hline nination & \\
\hline Fungal metabolites & \\
\hline
\end{tabular}

\section{Introduction}

Mycotoxins are fungal toxic metabolites produced by particularly by saprophytic molds growing on agricultural products. Some of these mycotoxins, including aflatoxins, are potentially carcinogenic and mutagenic with harmful effects to humans, livestock, and poultry. Aflatoxin was first identified in 1960 following a severe outbreak of a disease called "Turkey X Disease" in the UK that killed over 100,000 turkey birds (Pooja et al., 2015). It is now become a global food safety concern as recognized by the World Health Organization (WHO, 2008), with rural subsistence farming communities in developing countries being the populations most at risk of aflatoxin exposure. Staple foods that are susceptible to aflatoxin contamination, food insecurity, insufficient awareness and lack of enforcement of regulatory limits are some of the contributors to the high level of aflatoxin exposure in these populations (Yun et al., 2016). In many developing countries including Ethiopia, massive investments have been made to raise crop production levels to meet the 
food and nutritional needs of growing populations. Such efforts cannot attain its goals without lying due emphasis on the reduction of postharvest losses which are primarily by aflatoxins and mostly other fungal contaminations. It is common in most developing countries that even if aflatoxins impose great health and economic problem, it has been given little emphasis and has damaged a lot. Therefore, prevention and control strategies have to be primarily focused via environmentally friendly to fight against health and economic risk by aflatoxins (Soad et al., 2018).

\section{Population dynamics of the genus Aspergillus}

The genus Aspergillus which belongs to the phylum Ascomycota includes over 185 known species. Several members of Aspergillus section flavi produce aflatoxin. These includes Aspergillus flavus and Aspergillus parasiticus, as well as several less common taxa including Aspergillus nomius, Aspergillus tamarii, Aspergillus pseudotamarii, Aspergillus minisclerotigenes and Aspergillus bombycis (Matthias, 2009). Aspergillus species other than section flavi can also produce aflatoxins. For example, Aspergillus ochraceoroseus from section Ochraceoroseus; SCRR 1468, morphological resembling members of section Circumdati, and the Ascomycete Emericella astellata and E. venezuelensis (Aspergillus section Nidulantes, also produce aflatoxin (Cary et al., 2005). Aspergillus flavus is a ubiquitous and cosmopolitan filamentous fungus which proliferates in a wide range of environmental conditions. It is both a saprophytic and an opportunistic pathogen. Aspergillus section flavi can survive temperatures ranging from $12^{\circ} \mathrm{C}$ to $48^{\circ} \mathrm{C}$, with the optimal growth from $28^{\circ} \mathrm{C}$ to $37^{\circ} \mathrm{C}$, with a high humidity of above $80 \%$ (Matome et al., 2017).

\section{Life cycle and phases of infection}

Aspergillus section flavi most abundantly and widely distributed in soil or can be found anywhere such as on many organic nutrient sources like plant debris, tree leaves, decaying wood, animal fodder, cotton, compost piles, dead insects and animal carcasses, outdoor and indoor air environments, stored grains, and even on live humans and animals (Yu et al., 2005). Its life cycle in agricultural fields can be considered as
(1) colonization of plant debris in soil and (2) invasion of seeds and grain in actively growing crop plants (Fig. 1). Soil serves as a reservoir for primary inoculum of $A$. flavus and $A$. parasiticus (Matthias, 2009). A. parasiticus is more adapted to a soil environment, being prominent in peanuts, whereas $A$. flavus is more adapted to the aerial and foliar environment, being dominant in corn, cottonseed and tree nuts.

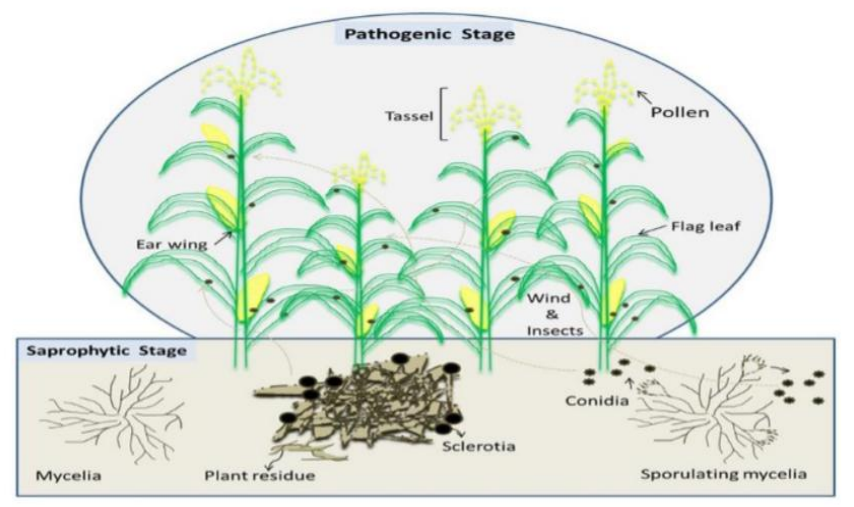

Fig. 1: Life cycle of A. flavus in a corn cropping system (Kiran et al., 2014).

Under adverse conditions the fungal mycelium congregates to form resistant structures called sclerotia, pigmented and compacted aggregates of hyphae which are capable of keeping dormant for long period of time ( $\mathrm{Yu}$ et al., 2005). The fungus overwinters either as mycelium in plant debris and litter on the soil, on insects or as sclerotia in the soil. When the growth conditions are favorable the sclerotia either germinate to produce additional hyphae or produce conidia or can be further dispersed to the soil or air. The fungus mostly exists in the form of mycelium or asexual conidia spores (Matthias, 2009).

A. flavus invades and infects developing seeds in the field before harvest, during harvest and in storage. Aflatoxin contamination can be divided into two distinct phases with the infection of the developing crop in the first phase and increase in contamination after maturation in the second phase (Cotty, 2001). Infections by $A$. flavus and $A$. parasiticus are promoted due to wounding of developing crops by birds, mammals, insects, mechanically or drought stress and elevated temperatures (Fig. 2). Its ability to attack seeds of both monocots and dicots, and to infect seeds produced both above and below the ground, 
demonstrates that this fungus has evolved a battery of mechanisms to breach the host's resistance. Conidia of plant, insect, and human derived strains of $A$. flavus rapidly colonize leaves, kernels, and insects injured during inoculation but do not affect uninjured plant or insect material ( $\mathrm{Yu}$ et al., 2005).

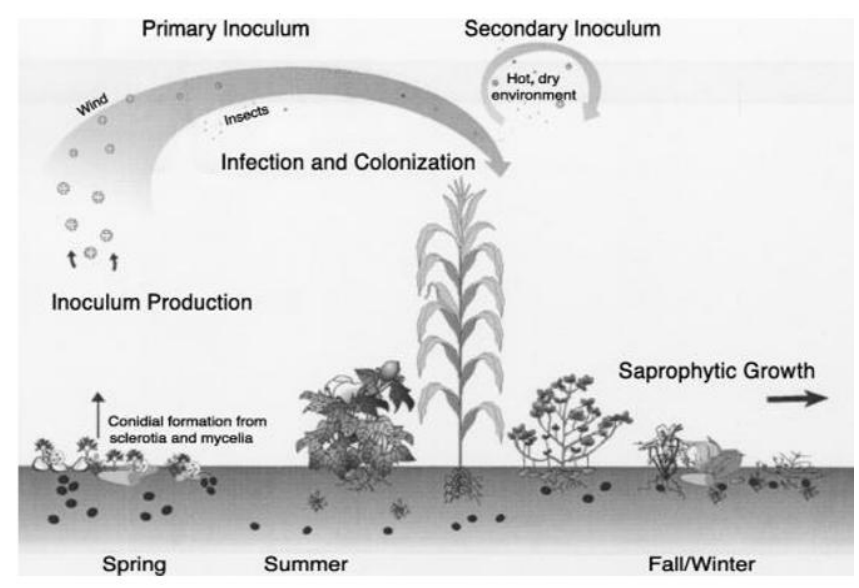

Fig. 2: Diagram of the pre-harvest infection of cotton, corn, and peanuts by Aspergillus flavus. Sclerotia and conidia produced by $A$. flavus growing on crop debris and in the soil serve as primary inoculum for young plants in the spring. Later in the growing season, conidia produced on crop debris or on infected plants provide high levels of secondary inoculum when environmental conditions are conducive for disease development (Matthias, 2009).

\section{Biology of aflatoxins}

Aflatoxins are a group of related fungal metabolites primarily produced by Aspergillus flavus and $A$. parasiticus. Aflatoxins, belongs to a group of difuranocoumarins, classified into two broad groups based on their chemical structure as: difurocoumarocyclopentenone and the difuro coumarolactone series. The four major naturally known aflatoxins are AFB1, AFB2, AFG1 and AFG2 (Jef et al., 2015).

The metabolic products of aflatoxins, M1 and M2 are first isolated from milk of lactating animals fed on aflatoxin contaminated grains and the reason why M designation (Bennett and Klich, 2003). Aflatoxins have closely similar structure (Fig. 3) and form a unique group of highly oxygenated heterocyclic compounds. Aflatoxins $\mathrm{B} 2$ and $\mathrm{G} 2$ were established as the dihydroxy derivatives of $\mathrm{B} 1$ and G1 whereas aflatoxin M1 is 4hydroxy aflatoxin $\mathrm{B} 1$ and aflatoxin $\mathrm{M} 2$ is 4-dihydroxy aflatoxin B2. Of the four major aflatoxins (B1, B2, G1 and G2), G2 occurs in high quantity and less toxic while B1 is the most toxic (Thrasher and Crawley, 2009). Insects and nematode vector infection increases fungal invasion and aflatoxin formation in the seeds (Pooja et al., 2015). Toxic moulds will invade agricultural products during plant growth, storage and processing. Kernels infected with fungal toxins such as aflatoxins may result in feed/food unsafe for consumption by humans or livestock. Aflatoxins have received considerable attention due to their effect in agricultural loss and livestock/ human health. Aflatoxin contamination of crops is a food safety concern throughout the world. The fungus continues to grow and produce toxin in poorly dried grain (Wafaa et al., 2014).
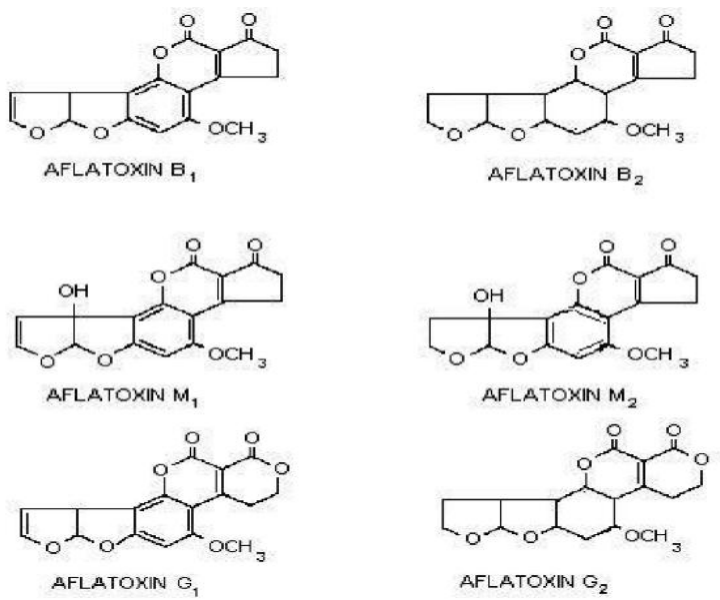

Fig. 3: Structure of Aflatoxins (where the "B" and "G" refer to the blue and green fluorescent colors produced under UV light on thin layer chromatography plates while the subscripts 1 and 2 indicate major and minor compounds, respectively whereas the $\mathrm{B}$ designation (B1 and B2) of aflatoxin results from the exhibition of blue fluorescence under UV-light, while the G designation have yellow-green fluorescence of the relevant structures (Sudakin, 2003).

\section{Worldwide aflatoxin exposure}

Dietary exposure to aflatoxin can be estimated by contamination level analysis of food samples combined with dietary intake surveys. Although these methods can be effective in estimating aflatoxin exposure levels in large samples, it has many limitations. For instance, dietary intake surveys are subjected to recall bias and social 
desirability issues, which could lead to under or over-estimation of exposure (Yun et al., 2016). Biomarkers are considered to be more accurate to measure the degree of individual exposure, as they are objective indicators and key determinants of internal dose and biologically effective dose. The biomarkers for aflatoxin exposure include the aflatoxin-N7-guanine adducts excreted in urine, which reflect the previous day's exposure; AFM1, the hydroxylated metabolite of AFB1, which is found in breast milk and reflects exposure over the previous 24 hours; and the aflatoxin-albumin adduct in plasma or serum, of a half-life of $\sim 2$ months, which permits the measurement of more chronic exposure to aflatoxin (Routledge and Gong, 2011). Aflatoxin exposure is not a major issue for developed countries, as there are strictly enforced regulatory limits in place and the diet is more diverse. Aflatoxin albumin is rarely detected in blood samples from populations in these regions. For instance, in a subset of 2051 individuals that participated in the 1999-2000 of National Health and Nutrition Examination Survey, which is a representative cross-sectional survey of the US population, only $1 \%$ had detectable levels $(\geq 0.02 \mu \mathrm{g} / \mathrm{L})$ of AFB1-lysine in their blood (Schleicher et al., 2013). There is high prevalence of aflatoxin exposure in Asian countries. For example a study examining aflatoxin exposure in pregnant women in South Asia using isotope dilution mass spectrometry to measure AFB1-lysine found detectable levels of the biomarker in $94 \%$ of blood samples collected from Nepalese pregnant women $(n=141)$, with levels ranging between 0.45 to $2939.30 \mathrm{pg} / \mathrm{mg}$ (Groopman et al., 2014). In the same study, AFB1lysine was detected in 63/63 (100\%) samples collected from pregnant women in their first and third trimester from Bangladesh, as well as in $63 / 63(100 \%)$ cord blood samples and in 63/63 (100\%) infants who were born to the mothers exposed to aflatoxin during pregnancy. In Africa, many reports has been dictating the higher contamination of cereals with aflatoxin and for instance in Ethiopia, aflatoxin contamination in different cereals and commodities and its effect have been investigated by many researchers such as Dereje et al., 2012 (Peanuts in Tigray); Chauhan et al., 2016 (Maize in Gedeo zone); Ezekiel et al., 2018 (Processed Beverages)) and others. Moreover, Urinary aflatoxins have been reported (Abebe et al., 2017).

\section{Impacts of aflatoxin}

Aflatoxin contamination is a significant problem worldwide (Assefa and Geremew, 2018) because it is a potent carcinogen and hepatotoxin (Soad et al., 2018) United States federal guidelines for food and feed set a limit of $20 \mathrm{ng} / \mathrm{g}$ total aflatoxins, while the European Union guidelines are more strict, with a limit of $1.0 \mathrm{ng} / \mathrm{g}$ limit for B1 and a 4.ong/g limit for total aflatoxins (Hamed et al., 2006). Aflatoxins are of a great concern and an emerging issue in many countries especially in humid tropics. Aflatoxin contamination is the main food safety problem for field crops produced in tropical and subtropical climate regions where high temperature and humidity promote growth and proliferation of Aspergillus spp. The International Agency for Research on Cancer categorized aflatoxins as class I carcinogens, as they are highly poisonous, toxic substances. Thus, exposure to aflatoxin-contaminated commodities imposes a great risk. Biological factors, harvesting, storage and processing conditions and climate change are the most important factors for mycotoxin infectivity (Rashad et al., 2018).

Foods and feeds, especially cereal grains, are susceptible to invasion by molds during preharvest, processing, transportation, or storage. Fungal growth is one of the main causes of cereal spoilage. It not only generates great economic losses, but also can cause acute or chronic intoxication to human and animals through the synthesis of mycotoxins. The most fungal toxigenic genera are Alternaria, Aspergillus, Fusarium and Penicillium (Osweiler, 2000). Alternaria and Fusarium species are among field fungi, while Aspergillus and Penicillium species are considered as storage fungi, although these can grow if environmental conditions are favorable (Ines et al., 2018).

The production of mycotoxins in commodities depends on both the environmental conditions and the toxigenic species present. Therefore, good harvesting and processing practices and early detection of mycotoxigenic species are key aspects in any strategy to prevent or reduce mycotoxins in foods. Precise and sensitive detection of the mycotoxigenic species is necessary since even very closely related species may produce a different array of mycotoxins (Sardinas et al., 2011). Cases of 
human and animal aflatoxicosis have been reported in Africa as a result of the consumption of food and feed contaminated with aflatoxins (Matome et al., 2017).

\section{Health impact of aflatoxin}

Aflatoxins are associated with various diseases; aflatoxicosis in livestock, domestic animals and human worldwide. Aflatoxicosis is resulted from ingestion of food or feed contaminated with aflatoxins. Aflatoxin poisoning is reported from all over the world in almost all domestic and nondomestic animals such as cattle, horse, rabbit, and other primates (Eva et al., 2011. There are four generally accepted dietary aflatoxins; B1, B2, G1 and G2 with toxicity rate $\mathrm{B} 1>\mathrm{G} 1>\mathrm{G} 2>\mathrm{B} 2$ (Ephrem, 2015). The metabolites, M1 and M2, are also found in milk. Aflatoxin M1 (AFM1) has been identified in the milk of dairy cows consuming AFB1-contaminated feeds (Kehinde et al., 2014). Aspergillus flavus is associated with many diseases of human, most severe of which is invasive aspergillosis. It also causes diseases in insects as well as in crops (Magoha et al., 2014). Different mycotoxins have also been reported as contaminant of poultry feed, most important of which are aflatoxins (B1, B2, G1, G2) and Ochratoxin A there by induce various diseases (Eva et al., 2011) (Table 1).

Table 1. Major diseases caused by aflatoxicosis in some animal species (Eva et al., 2011).

\begin{tabular}{|c|c|c|}
\hline $\begin{array}{l}\text { Animal } \\
\text { Species }\end{array}$ & Disease imposed by Aflatoxins & Symptoms \\
\hline Horses & $\begin{array}{l}\text { When eating: Liver damage, centrilobular hepatic } \\
\text { necrosis phagocytosed haemosiderin in Kupffer cells, } \\
\text { bile-duct hyperplasia, congestion of renal vessels and } \\
\text { adrenal cortex. } \\
\text { When inhaling: Chronic obstructive pulmonary disease } \\
\text { (COPD), yellow-brown liver with centrilobular necrosis, } \\
\text { icterus hemorrhage, tracheal exudates and brown urine. }\end{array}$ & $\begin{array}{l}\text { When eating: Anorexia, icterus, rapid } \\
\text { weight loss and dead. } \\
\text { When inhaling: Chronic cough, nasal } \\
\text { discharge, expiratory dyspnoea reduced } \\
\text { exercise tolerance, inappetence, } \\
\text { depression, fever, tremor, ataxia, cough } \\
\text { and dead. }\end{array}$ \\
\hline Chickens & $\begin{array}{l}\text { Immunosuppression, liver and kidney damage, periportal } \\
\text { fatty infiltrations, increase in connective tissue, } \\
\text { hemorrhages, susceptibility to opportunistic infectious } \\
\text { agents and poor response to vaccination programs. }\end{array}$ & $\begin{array}{l}\text { Low productivity, low growth, low weight, } \\
\text { low stance, but no evident clinical } \\
\text { symptoms and death. }\end{array}$ \\
\hline Swine & $\begin{array}{l}\text { Immunosuppression, expression of opportunistic } \\
\text { infections, liver swollen, liver congestion, hydrothorax, } \\
\text { edematous gall bladder, petechiated and ecchymotic } \\
\text { mucosa, extensive centrilobular liver necrosis, } \\
\text { hemorrhage, hepatic centrilobular cellular Infiltration, } \\
\text { hepatocyte swelling, bile stasis, hepatocyte vacuolation } \\
\text { and bile ductile hyperplasia. }\end{array}$ & $\begin{array}{l}\text { Low growth rate, gastrointestinal } \\
\text { problems, anoroexia, ill thrift and dead. }\end{array}$ \\
\hline Cattle & $\begin{array}{l}\text { Fibrosis with biliary proliferation in livers, venocclusive } \\
\text { disease increase in connective tissues, degeneration of } \\
\text { centrilobular hepatic cells, proliferation of connective } \\
\text { tissue, generalized liver damage and immunosuppression. }\end{array}$ & Icterus, rapid weight loss and dead \\
\hline $\begin{array}{l}\text { Other } \\
\text { Animals }\end{array}$ & $\begin{array}{l}\text { Pulmonary edema, generalized liver damage, } \\
\text { coagulopathy, capillary fragility, hemorrhage, prolonged } \\
\text { clotting times, urine pigmentation, icterus and hepatic } \\
\text { injury. }\end{array}$ & $\begin{array}{l}\text { Depression, anorexia, weight loss, } \\
\text { bleeding, decline in feed consumption and } \\
\text { production, gastro intestinal damage and } \\
\text { death. }\end{array}$ \\
\hline
\end{tabular}

Aflatoxins are among the most studied groups and apart from producing clinical toxicosis they also reduce the resistance to diseases and interfere with vaccine induced immunity in poultry birds. Agricultural commodities contaminated with toxigenic fungi like $A$. flavus can be injurious for animals and human health. Production of mycotoxins is species specific; therefore, proper identification and characterization of fungi is of prime importance to develop preventive strategies (UNICEF, 2012). Regular monitoring of toxic mycoflora of agricultural based feeds and foods is 
an essential pre-requisite for development of strategies to control or prevent mycotoxins exposure of feed animal and human population (Fakruddin et al., 2018).

In Africa, weaning foods are often cereals and legumes of which are susceptible to aflatoxin contamination and as a result children exposure increases during weaning. Aflatoxins have been recently considered as an important sanitary problems because it has been demonstrated that human exposure to mycotoxins may result from consumption of plant derived foods that are contaminated with aflatoxins and their metabolites which can also be present in animal products like milk, meat, visceral organs and eggs or exposure to air and dusts (Kiran et al., 2014).

It has been reported that, because of their low molecular weight, aflatoxins upon ingestion can be rapidly adsorbed in the gastro-intestinal tract through a non-described passive mechanism, and then quickly appear as a metabolite in blood after just 15 minutes and in milk as soon as 12 hours post-feeding (Eva et al., 2011). High exposure of aflatoxin over a relatively short time causes acute aflatoxicosis. Although acute aflatoxicosis occurs on a case by case basis, large outbreaks have been reported in Africa and chronic aflatoxicosis due to low dose aflatoxin exposure over a long period of time is reported more prevalent than acute aflatoxicosis. The most well established health effect of chronic exposure are hepatocellular carcinoma impaired child growth and immune suppression (Azziz Baumgartner et al., 2005) (Fig. 4).

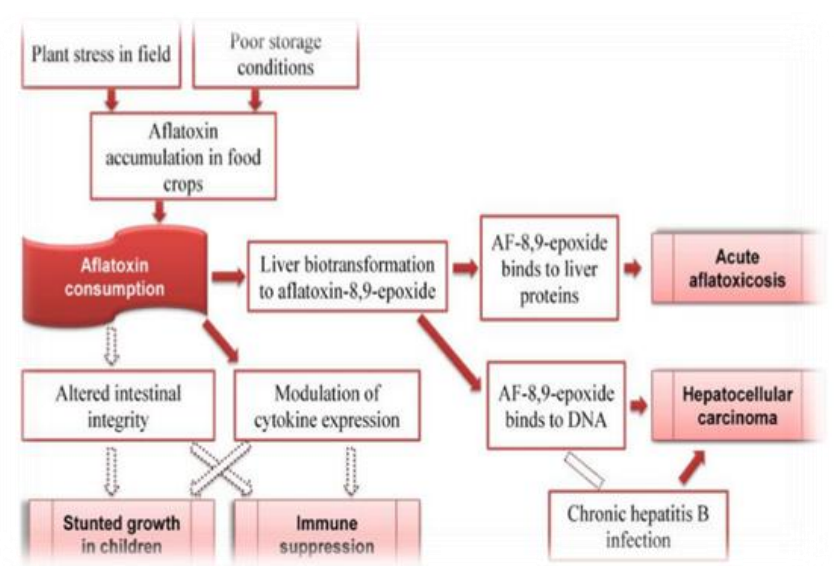

Fig. 4: Aflatoxin disease pathways in human Beings (Azziz Baumgartner et al., 2005).

\section{Hepatocellular carcinoma}

Hepatocellular carcinoma is recognized as the sixth most common cancer worldwide, with $83 \%$ of cases occurring in less developed countries and the highest incidence rates are observed in Asia and Africa (Bosett et al., 2014). Aflatoxin, owing to its mutagenic and carcinogenic properties, has been classified as a major risk factor, alongside the hepatitis $\mathrm{B}$ and $\mathrm{C}$ virus. In fact it has been shown that aflatoxin and hepatitis $\mathrm{B}$, which is also highly prevalent in Africa and South Asia, can synergistically interact, resulting in an increased risk of hepatocellular carcinoma (Wu et al., 2009). The P53 gene hotspot mutation at codon 249 is associated with aflatoxin exposure. Villar et al (2011) observed a seasonal variation in levels of the R249S mutation in circulating cell free DNA in the serum of subjects in Gambia that reflected seasonal variations in aflatoxin exposure and markers of HBV infection, an interaction of these risk factors lead to liver cancer. Aflatoxin has also been implicated in the aetiology of other liver diseases including cirrhosis and hepatomegaly. A study in Kenya by Gong et al (2012) reported that the prevalence of hepatomegaly, a firm liver enlargement, increased in children with higher aflatoxin exposure. This proves the fact that liver is the key target organ for aflatoxin toxicity.

\section{Impaired child growth}

The first 1000 days of life are critical periods for healthy growth and development and dietary intake during pregnancy plays a key role in the child's future health. In sub-Saharan Africa, malnutrition and impaired child growth are major public health burdens. The impact of aflatoxin on growth impairment at different time points has been investigated as:

\section{Utero exposure}

Various studies have been reported that aflatoxin exposure can occur in utero through a transplacental pathway and higher exposure levels in utero have been associated with lower birth weights and stunted child growth (Shuaib et al., 2010). It has been suggested that epigenetic changes, which may occur as a consequence of aflatoxin exposure in utero, is a potential mechanism to explain this relationship. A study by 
Hernandez-Vargas et al (2015) examined the consequences of in utero exposure to aflatoxin on the white blood cell DNA global methylation level in children aged 2-8 months. Differential methylation of genes, including some growth and immune function related genes are associated with AF-alb exposure.

\section{Breast milk exposure}

Although breast milk is full of nutritional and immunological components, it is the potential source of aflatoxin exposure for very young infants. $\mathrm{AFM} 1$, the hydroxylated metabolite of $\mathrm{AFB} 1$, is typically detected in breast milk 12 to 24 hours following ingestion of foods contaminated with AFB1 (Yun et al., 2016). Only a few epidemiological studies have investigated the relationship between AFM1 in breast milk samples and impaired child growth. Magoha et al (2014) examined the relationship between AFM1, measured in breast milk samples of 143 lactating mothers, and growth impairment in their infants under 6 months of age in Northern Tanzania with mean AFM1 exposure concentrations of the infants at months 1,3 and 5: $11.08 \pm 10.13$, $11.94 \pm 9.69$ and $10.91 \pm 6.82 \mathrm{ng} / \mathrm{kg}$ bodyweight/day, respectively. This highlights the potential for exposure of AFM1 from breast milk contributing to child growth impairment. The WHO recommendation of exclusive breast-feeding until 6 months of age should be encouraged owing to the high nutritional content and immunological properties of breast milk. Furthermore, infants who are exclusively breastfed appear to have lower AF-alb concentrations compared to those partially breastfed and fully weaned (Magoha et al., 2014). It must, therefore, be remembered that prolonged breastfeeding is protective to child health.

\section{Exposure via weaning food}

Children of weaning age in developing countries, especially sub-Saharan Africa, are considered a high-risk population group for aflatoxin exposure (Gong et al., 2008). Maize and groundnuts, which are typical constituents of weaning foods, are highly susceptible to aflatoxin contamination (Egal et al., 2005). Level of exposure relative to body weight is higher for children than for adults and the rapid growth that occurs, and the additional nutrients required during this time. It has been reported that stunted growth is highly prevalent in parts of Africa and South Asia. For instance, in East and West Africa near to $42 \%$ and $36 \%$ respectively and approximately $36 \%$ of Southcentral Asian children aged less than 5 years have stunted growth and the effects have also been investigated in older children (UNICEF, 2012). This is attributed to the consumption of aflatoxin contaminated food and other associated factors.

\section{Potential mechanisms}

It has been suggested that aflatoxin exposure may disrupt the insulin-like growth factors (IGF) pathway through liver toxicity (Yun et al., 2016). Other potential mechanisms for the aflatoxin child growth impairment include the immunesuppressive effect of aflatoxin exposure that may increase infection susceptibility, consequently impairing nutritional status through appetite suppression and reduced nutrient absorption (Gong et al., 2008). Smith et al. (2012) postulated that exposure to aflatoxin may promote intestinal damage through protein synthesis inhibition, consequently leading to a reduction in the absorption of essential nutrients and subsequent impaired growth. The reactive aflatoxin-8, 9epoxide preferentially binds to mitochondrial DNA during hepatocarcinogenesis and causes the disruption of mitochondrial functions and triggers ATP production which is required by various parts of the body. Mitochondrial damage can also leads to mitochondrial diseases and may be responsible for aging process (WHO, 2008) As the mitochondria get diseased, the nucleus detect energetic deficits in its area and attempts to compensate for the ATP shortages by triggering the replication of any nearby mitochondria but unfortunately, the response will promote mitochondrial replication that are causing the local energy deficit hence aggravating the problem (Wallace, 1997). The AFB1 also binds to DNA and cause structural changes to the DNA and leads to gene mutation as well as change in telomere length and the check points in the cell cycle. The binding of AFB1 to DNA at the guanine base in liver cells corrupts the genetic codes which regulate cell growth and thereby lead to tumor formation. Therefore, the reactive aflatoxin-8, 9-epoxide can affect the cell cycle at various stages by disrupting the various check points and furthermore exposure to aflatoxins leads to sperm aberration in mice 
(Ezekiel et al., 2011). Earlier, aflatoxins have been reported to be genotoxic in in-vivo sperm head abnormality tests (Fapohunda et al., 2008). This indicates that aflatoxins will result infertility.

\section{Immune suppression}

The immunosuppressive effects of aflatoxin, which include reduced antibody production, increased susceptibility to infectious diseases and reduced cell-mediated immunity, have been thoroughly investigated in many animal species (Bondy and Pestka, 2000). In humans the immunosuppressive effects of aflatoxin exposure, however, have not clearly been established, as only a limited number of studies have been conducted. A study conducted in the Gambia (Turner et al., 2003) found a reduction in the secretary Immunoglobulin A antibody in children (aged 6 to 9 years) with detectable AF-alb concentrations blood $(n=432)$ compared to those with non-detectable levels ( $\mathrm{n}=$ 32). The sIgA is an important component of the mucosal barrier that protects against infectious diseases and uptake of harmful micro-organisms. This reduced level of sIgA driven by aflatoxin exposure could be a potential mechanism for the impaired child growth that was also observed in this cohort. The high prevalence of aflatoxin exposure coincides geographically with the high prevalence of the human immunodeficiency virus (HIV) in Africa. It has been suggested that the immunosuppressive effects of aflatoxin exposure may accelerate the progression of HIV (there is evidence to show that HIV positive individuals with high aflatoxin exposure, have lower levels of immune markers such as CD4 $+\mathrm{T}$ regulatory cells $(\mathrm{P}=0.009)$ and naive $\mathrm{CD} 4+\mathrm{T}$ cells $(\mathrm{P}=0.029)$, as well as lower percentages of type $\mathrm{B}$ lymph cells ( $\mathrm{P}$ $=0.03$ ), compared to HIV positive individuals with low aflatoxin exposure) (Jiang et al., 2008).

\section{Control of aflatoxins/aflatoxigenic fungi}

\section{Chemical and physical control}

Wide range of chemicals such as sodium hydroxide, ammonium hydroxide, sodium hypochlorite, hydrogen peroxide and ozone (Tiwari et al., 2010) with different efficacy and selectivity are being used to degrade several types of mycotoxins. The main problems with these chemical and physical methods are their limited range of effect on various mycotoxins and some chemicals may lead to deterioration in animal health. Additionally, it causes a significant reduction in the quality of food products (Gowda et al., 2013). Adsorption is well investigated treatment among physical techniques. Studies related to this field refer to the alleviation of mycotoxicosis by the adsorption of a large molecular weight compound. Animal feed studies have demonstrated that clay additives, such as bentonites (containing smectites such as montmorillonite) minerals, can bind aflatoxins in ingested feed and reduce or eliminate the toxicity (Jaynes and Zarman, 2011). The surface of these minerals can be treated with organic compounds to create surface-modified clays which remove some contaminants more effectively than the untreated clay. These compounds can be applied as mycotoxin sequestering agents in animal feed or as mycotoxin adsorbing agents to seclude the toxic compounds usually in vitro and in vivo (Merrill et al., 2007).

Aflatoxin can be degraded from food by irradiation of sunlight, $\gamma$-radiation, or microwave (Herzallah et al., 2008). Microwave-induced argon plasma can degrade aflatoxin B1, deoxynivalenol and nivalenol in artificial solutions within seconds (Park et al., 2007). On similar line, alkaline electrolyzed water can be a candidate for the removal of aflatoxin from edible plant oils through physico-chemical action at low levels of infection with high efficacy (Fan et al., 2013). Ozone is also one of the most powerful disinfectants and sanitizing agents for aflatoxins. It has been approved as generally recognized as safe which means it can be directly applied as an antimicrobial agent in the food industry (Inan et al., 2007). A most attractive aspect of ozone is that, after reaching its half-life (20-50 min), decomposition products do not represent any hazard for the treated materials (Karaca and Velioglu, 2014). In post-harvest treatment, gaseous and aqueous ozone phases are applied to inactivate bacterial growth, prevent fungal decay, destroy pesticides and chemical residues, control storage pests, and degrade aflatoxins (Patchimaporn et al., 2017). The mechanisms of ozone to inhibit microbial populations in food occur via the progressive oxidation of vital cellular components. It oxidizes polyunsaturated fatty acids or sulfhydryl group and amino acids of enzymes, 
peptides, and proteins to shorter molecular fragments. In addition, ozone degrades the cell wall envelope of unsaturated lipids resulting in cell disruption and subsequent leakage of cellular contents (Das et al., 2006). The mechanism of ozone on the degradation of AFB1 and AFG1 involves an electrophilic reaction on the C8-C9 double bond of the furan ring causing the formation of ozonide (Diao et al., 2013). Since there is no C8-C9 double bond in the structure, $\mathrm{AF}-\mathrm{B} 2$ and $\mathrm{AF}-\mathrm{G} 2$ are more resistant to ionization than AF-B1 and AF-G1 (Agriopoulou et al., 2016). Even though the efficiency of ozone as a chemical detoxifier is high, a greater concentration is required to kill fungi or contaminated surfaces, while low concentration of ozone and short fumigation time is generally considered necessary in order to preserve product properties like colour, flavor, aroma, and vitamins (Chen et al., 2014). Among the different type of mycotoxins, aflatoxins are widespread in major food crops such as maize, groundnuts, tree nuts, and dried fruits and spices as well as milk and meat products there by inducing great health and economic crisis (Zeinvand-Lorestani et al., 2015). Due to these effects, different countries and international organizations have established Safe limit regulations in order to control aflatoxin contamination in food and feeds and also to prohibit trade of contaminated products (Juan et al., 2012).

The regulations on "acceptable health risk" usually depend on a country's level of economic development, extent of consumption of high-risk crops, and the susceptibility to contamination of crops to be regulated (Kendra and Dyer, 2007). Indeed, the established safe limit of AFs for human consumption ranges 4-30 $\mathrm{mg} / \mathrm{kg}$. The EU has set the strictest standards, which establishes that any product for direct human consumption cannot be marketed with a concentration of AFB1 and total aflatoxins greater than $2 \mathrm{mg} / \mathrm{kg}$ and $4 \mathrm{mg} / \mathrm{kg}$, respectively (EC, 2010). Likewise, US regulations have specified the maximum acceptable limit for $\mathrm{AFs}$ at $20 \mathrm{mg} / \mathrm{kg}$ (Wu, 2006). However, if the EU aflatoxin standard is adopted worldwide, lower income countries such as those in Asia and SubSaharan Africa will face both economic losses and additional costs related to meeting those standards. This situation requires alternative technologies at pre- and post-harvest levels aimed to minimize contamination of commercial foods and feeds, at least to ensure that aflatoxin levels remain below safe limits (Prietto et al., 2015). Nowadays, there is an increase in the reported number of possible aflatoxin degrading bioremediators, with microorganisms or enzymes (Giovati et al., 2015). Many species of bacteria and fungi have been shown to enzymatically degrade aflatoxins (Zsolt et al., 2017).

\section{Biological control}

Biological control using microbial antagonists either alone or integrated to reduce pesticide inputs has emerged as a promising approach for control of aflatoxins in both pre- and post-harvest systems (Zsolt et al., 2017). Good agricultural practices such as timely planting, maintaining optimal plant densities, avoiding drought stress, providing adequate nutrition and weed control, controlling pathogens and pests, and following proper harvesting practices should be employed to reduce the incidence of aflatoxin contamination in the field (Ehrlich and Cotty, 2004). Crop rotation and residue management also play an important role in controlling A. flavus infection in the field (Waliyar et al., 2013). Soil amendments like lime application, use of cereal crop residues, and farm yard manure have also been reported as effective management practices. Several organisms including bacteria, yeasts and non-toxigenic Aspergillus fungi have been tested for their ability to reduce mycotoxin contamination (Dimitrios et al., 2012). Even if the use of biocontrol agents has often been successful in the lab, its commercialization largely depends on whether it can consistently control fungi in different locations and cultivars thereby reduce mycotoxin levels below the legislative limits. The use of microorganisms as biocontrol agents has relatively narrow spectrum of activity as compared to most chemical fungicides. It is a complex process which involves a number of variables. In addition to efficacy towards the targeted plant pathogen, the new biocontrol products must be safe and cost-effective (Kohl et al., 2011). Despite all these problems, a number of successful commercial products have been launched to the market worldwide for mycotoxigenic fungi control, including Aspire (Candida oleophila strain 182; Ecogen Inc., Langhorne, PA), BioSave 10 and 11 (Pseudomonas syringae strains ESC10 and ESC 11; 
Eco Science Corp., Worcester, MA), AF36 (atoxigenic strain of $A$. flavus) (Cotty, 1998), and Afla-Guard (atoxigenic strain of $A$. flavus NRRL 21882) (Dorner and Lamb, 2006). Advances in biological control have been supported by advances in molecular biology, genetic engineering and microbial genomics coupled with the discovery of the broad microbial catabolic potential. A. flavus has no known sexual stage and consequently most studies on its genetic variability have been made mainly by characterizing isolates based on vegetative compatibility. Complementary nitratenon utilizing (nit) mutants are commonly used to identify compatible isolates (Dimitrios et al., 2012). There are numerous reports regarding to the antifungal activities of various lactic acid bacteria, which can act against several Aspergillus species and a broad range fungi. During carbon source metabolism, it produces antimicrobial compounds such as lactic acid, acetic acids, hydrogen peroxide, bacteriocins, and lowmolecular-weight proteinaceous compounds and they compete with other species by environment acidification the and rapid nutrient depletion (Kabak and Dobson 2009). For example, it is earlier reported the antifungal activity of a Lactobacillus casei strain which inhibited both growth and aflatoxin production in $A$. parasiticus (El- Gendy and Marth, 1981). Coallier-Ascah and Idziak (1985) also reported that Streptococcus lactis cultures significantly reduced aflatoxin production by $A$. flavus and also antifungal activity from a Leuconostoc mesenteroides strain was reported (Suzuki et al., 1991). Another isolate from a silage inoculant of Lactobacillus casei pseudoplantarum, has also been reported to inhibit production of AFB1 and AFG1 by 80 and $92 \%$, respectively (Gourama and Bullerman, 1997). Research by Corsetti et al. (1998) reported the antifungal activity of Lactobacillus sanfrancisco CBI, caused by the formation of short-chained fatty acids such as caproic acid and inhibited spoilage moulds from the genera Monilia, Aspergillus, Penicillium, and Fusarium. Moreover, aflatoxin inhibition by metabolites such as benzoic acid, cyclo (Gly-L-leucyl) methylhycantoin, and nevalon actone produced by specific lactic acid bacteria has been reported (Kabak et al., 2006). In addition to the use of biocontrol agents in the field or at postharvest level, a number of fungal or bacteria cultures have been shown to detoxify AFB1. Fungal taxa such as Trichoderma, Phoma, Rhizopus,
Sporotrichum sp. ADA, Sporotrichum sp. SF, and Alternaria species have been shown to degrade AFB1 by $65-99 \%$ within 5 days at $28 \pm 2{ }^{\circ} \mathrm{C}$ (Enyiukwu et al., 2014). Flavobacterium aurantiacum can also significantly remove AFB1 from a liquid medium and a variety of food products including milk, peanuts, and corn without leaving toxic by-products. Fusarium aurantiacum strain NRRL-B-184 is reported to remove 79.998.9\%, 92.699.8\%, and 88.7-100\% AFB1 from phosphate-buffered saline, peanuts and red pepper, respectively within $48 \mathrm{~h}$ (Dimitrios et al., 2012).

One of the recent biological approaches which have proved effective under field conditions is the use of nonaflatoxigenic fungal strains which competitively exclude aflatoxigenic fungi (Zanon et al., 2013; Navya et al., 2017). Afla-Guard® (A. flavus strain NRRL 21882) is the first commercialized non-aflatoxigenic strain followed by AF36 (A. flavus strain NRRL 18543) and K49 (A. flavus strain NRRL 30797) recommended for use in groundnut, maize and cotton production, respectively in USA (Accinelli and Abbas, 2011). Similarly, in different parts of Africa, Afla-safe ${ }^{\mathrm{TM}}$, which is a mixture of four native atoxigenic strains, is in use to manage aflatoxins in maize and groundnut production (Probst et al., 2011). Further, bioplastic based granular formulation of non-aflatoxigenic $A$. flavus has been developed and successfully tested under filed conditions as soil and foliar applications (Accinelli et al., 2016).

\section{Phytofungicides}

Several edible plant extracts have been reported to have antifungal activity. Essential oils extracted from various plants have been shown to possess significant antifungal properties. The inhibitory effects of plant extracts on aflatoxin synthesis have also been examined well. The extract of Azadirachta indica was observed to be a good inhibitor of both growth of $A$. flavus and $A$. parasiticus, and toxin production in vitro. The Ocimum canum oil exhibits a broad range of activity against fungi, including human pathogens (Pradeep et al., 2003). Phenolic pulp extract of Dialium guineense has been proved effective for the prevention of lipid peroxidation, proteins oxidation and DNA fragmentation by AFB1 (Adeleye et al., 2014). Another adsorbent prepared 
from bagasse has been proved effective for detoxification of AFB1 in the gastrointestinal tract of chicks and no negative symptoms was reported (Khan and Zahoor, 2014).

Aflatoxin oxidase, an enzyme of Armillariella tabescens presents a detoxifying activity towards AFB1. This reaction is dependent on oxygen and hydrogen peroxide producing, which may play the crucial role in detoxification of aflatoxin oxidase (Wu et al., 2015). Laccase enzyme also has proven detoxifying affinity for AFB1 (Zeinvand-Lorestani et al., 2015). Furthermore, Manganese peroxidase is an enzyme of Pleurotus ostreatus which may detoxify AFB1 according to the enzyme concentration and the incubation period (Mohamed and Aminata, 2016). In an evaluation by Hussain et al. (2012), it has been found that; clove, clove oil, and Allium spp. completely inhibit the growth of Aspergillus flavus and A. parasiticus in laboratory. In Cameroons, Tagne et al. (2008) showed that Ocimum gratissimum, Cymbopogon citrates and Thymus vulgaris extracts and essential oils retarded the development of Fusarium verticilliodes in maize both on-farm and in-vitro. According to Thana (2011), betel vine leaf completely inhibited growth and aflatoxin production of $A$. flavus while tobacco extracts $(<10 \% \mathrm{w} / \mathrm{v})$ significantly inhibited the fungus in culture. Neem-derived azadirachtin a norterpenoid is also a well-known aflatoxin inhibitor (Allameh et al., 2011). Neem oil (0.54.0\% v/v) in a trial as noted by Da Costa et al (2010) resulted in 95\% inhibition of aflatoxin B1 and B2 in vitro but failed to suppress the fungal growth.

Coffee leaves and fruits rich in caffeine alkaloids also showed antifungal activity against species of Penicillium and Aspergillus which works through inhibition of respiratory systems of the fungus or their glucose uptake necessary for production of acethyl CoA. Aqueous extracts of Zingiber offcinale and leaf extracts of Trignoella faenum-graecum inhibited aflatoxin production to significant levels while solvent extracts of Oxalis corniculata and $Z$. offcinale inhibited both growth and aflatoxin production of A. flavus (Reddy et al., 2011). Oil of Nigella sativum (1-3\%) completely inhibited aflatoxin production while fruit extract of baobab inhibited total aflatoxin production by $A$. parasiticus by $69.1 \%$ (El-Nagerabi et al., 2013). Aqueous seed extracts from Carica papaya is rich in the alkaloid carpaine which has high antioxidant activity and reported to be responsible for antimycotoxigenic action (Enyiukwu et al., 2014).

\section{Genetic engineering of crop plants for resistance to Aspergillus infection}

Genetic engineering technology is crucial to develop beneficial plant traits with higher ability to resist attack by insects and pathogens and increasing crop yields (Amalu, 2004). Development of such transgenic varieties is extremely valuable and will be an aid to breeding tools. Genome segments from the pathogenic fungi have been widely used to make transgenic plants varieties for increasing or decreasing the expression of several genes responsible for antifungal or anti-toxin activities. The availability of modern and efficient biotechnological tools which aid the evaluation of plant-pathogen protein interactions, genomics and field ecology of the fungus has encouraged researches on transgenic approaches to control invasion of cereals by Aspergillus (Enyiukwu et al., 2014). Various antifungal proteins and peptides have been isolated from a wide range of plants and tested for their antifungal activity against several Aspergillus species (Rajasekaran et al., 2009). Antifungal proteins and peptides used in genetic engineering of susceptible crop species to against A. flavus infection and aflatoxin contamination include defensins, thionins, plant non-specific lipid transfer proteins, knottins, impatiens antimicrobial peptides, ribosome inactivating proteins, lectins, and lectin-like peptides. Research strategies have been developed to control expression of stress-responsive genes through engineering of the regulatory machinery by using transcription factors and gene pyramiding instead of insertion of "single-action" genes (Prasad et al., 2012).

\section{Conclusion}

Aflatoxins are potentially carcinogenic and mutagenic with harmful effects to humans, livestock, and poultry. Aflatoxin contamination is a significant problem worldwide because it is a potent carcinogen and hepatotoxin. High exposure of aflatoxin over a relatively short time causes acute aflatoxicosis. The most well established health effect of chronic exposure are hepatocellular 
carcinoma impaired child growth and immune suppression. This aflatoxin development can be both prevented and controlled. It can be prevented via good agricultural practices and by the use of appropriate measures and can also be controlled by using physical, chemical and biological measures. The biological method is safer and environmentally friendly which have no side effect if properly applied. More recently, biotechnological tools enable to develop resistant plant varieties and this opens the path of reliable and sustainable aflatoxin detoxification, but not widely utilized in developing countries due to sophisticated technology and limited research. This review recommends countries shall focus on biological detoxification strategies being supported with biotechnological researches.

\section{Conflict of interest statement}

Authors declare that they have no conflict of interest.

\section{References}

Abebe, A., Ashagrie, ZW., Abdulaziz, A., Marthe, De B., Ellen, H., Sarah De, S., 2017. Assessment of aflatoxin exposure among young children in Ethiopia using urinary biomarkers. Food Addit. Contam. 34(9), 1606-1616.

Accinelli, C., Abbas, H., Vicari, A., Shier, W., 2016. Leaf application of a sprayable bioplastic-based formulation of biocontrol Aspergillus flavus strains for reduction of aflatoxins in corn. Pest Manage. Sci. 72, 1521-1528.

Accinelli, C., Abbas, H. K., 2011. New perspectives for the application of bioplastic materials in the biocontrol of Aspergillus flavus in corn. Toxin Rev. 30, 71-78.

Adeleye, A. O., Ajiboye, T. O., Iliasu, G. A., Abdussalam, F. A., Balogun, A., Ojewuyi, O. B., 2014. Phenolic extract of Dialium guineense pulp enhances reactive oxygen species detoxification in aflatoxin B1 hepato carcinogenesis. J. Med. Food. 17(8), 875-85.

Agriopoulou, S., Koliadima, A., Karaiskakis, G., Kapolos, J., 2016. Kinetic study of aflatoxin degradation in the presence of ozone. Food Control. 61, 221-226.

Allameh, A., Ziglari, T., Rasooli, I., 2011. Phytoinhibition of growth and aflatoxin biosynthesis in toxigenic fungi: Aflatoxins - detection, measurement and control. TorresPacheco (Eds). In Tech Croatia, pp.283-316.

Amalu, U., 2004. Plant biotechnology and food crop development in sub-Saharan Africa. Technol. Soc. 26, 537-550.

Azziz-Baumgartner, E., Lindblade, K., Gieseker, K., 2005. Case-control study of an acute aflatoxicosis outbreak, Kenya, 2004. Environ. Health Perspect. 113, 1779-1783.

Bennett, J. W., Klich, M., 2003. Mycotoxins. Clin. Microbiol. Rev. 16(3), 497-516.

Bondy, G. S., Pestka, J. J., 2000. Immuno modulation by fungal toxins. J. Toxicol. Environ. Health. 3, 109-143.

Bosetti, C., Turati, F., La Vecchia, C., 2014. Hepatocellular carcinoma epidemiology. Best Prac. Res. Clin. Gastroenterol. 28, 753-770.

Cary, J. W., Klich, M. A., Beltz, S. B., 2005. Characterization of aflatoxin-producing fungi outside of Aspergillus section flavi. Mycologia. 97, 425-432.

Chauhan, N., Alemayehu, W., Tesfaye, M., 2016. Fungal infection and aflatoxin contamination in maize collected from Gedeo zone, Ethiopia. Springer Plus. 5, 753-761.

Chen, R., Ma, F., Li, P., Zhang, W., Ding, X., Zhang, Q., 2014. Effect of ozone on aflatoxin detoxification and nutritional quality of peanuts. Food Chem. 146, 284-288.

Coallier-Ascah, E. S., Idziak, J., 1985. Interaction between Streptococcus lactis and Aspergillus flavus on production of aflatoxin. Appl. Environ. Microbiol. 49, 163-167.

Corsetti, A., Gobbetti M. J., Rossiand, D., 1998. Anti-mould activity of sourdough lactic acid bacteria: Identification of a mixture of organic acids produced by Lactobacillus sanfrancisco CB1. Appl. Microbiol. Biotechnol. 50, 253-256.

Cotty, P. J., 1998. Use of native Aspergillus flavus strains to prevent aflatoxin contamination. U.S. Patent. 5, 171- 686.

Cotty, P. J., 2001. Cottonseed losses and mycotoxins; Compendium of Cotton Diseases. In: Kirkpatrick, T.L., Rothrock, C.S. (Eds.). Amer. Phytopathol. Soc. 1, 9-13.

Da Costa, C. L., Geraldo, M. R. F., Arroteia, C. C., Kemmelmeier, C., 2010. In vitro activity of neem oil on Aspergillus flavus growth, sporulation viability of spores, morphology and aflatoxin B1 and B2. Adv. Biosci. Biotechnol. 1, 292-299.

Das, E., Gürakan, G. C., Bayindirli, A., 2006. Effect 
of controlled atmosphere storage, modified atmosphere packaging and gaseous ozone treatment on survival of Salmonella enteritis on cherry tomatoes. Food Microbiol. 23(5), 430438.

Dereje, A., Muez, T., Helge, S., 2012. Natural occurrence of toxigenic fungi species and aflatoxin in freshly harvested groundnut kernels in Tigray, Northern Ethiopia. J. Drylands. 5(1), 377-384.

Diao, E., Hou, H., Chen, B., Shan, C., Dong, H., 2013. Ozonolysis efficiency and safety evaluation of aflatoxin B1 in peanuts. Food Chem. Toxicol. 55, 519-525.

Dimitrios, I. T, Myrto, D., Polymnia, P., Antoniou, Eleftherios, C. T., 2012. Biological control strategies of mycotoxigenic fungi and associated mycotoxins in Mediterranean basin crops. Phytopathol. Mediter. 51(1), 158-174.

Dorner, J. W., Lamb, M. C., 2006. Development and commercial use of Afla-guard, an aflatoxin biocontrol agent. Mycotoxin Res. 21, 33-38.

Egal, S., Hounsa, A., Gong, Y.Y., 2005. Dietary exposure to aflatoxin from maize and groundnut in young children from Benin and Togo, West Africa. Int. J. Food Microbiol. 104, 215-224.

Ehrlich, K. K., Cotty, P. J., 2004. An isolate of Aspergillus flavus used to reduce aflatoxin contamination in cotton seed has a defective polyketide synthase gene. Appl. Microbiol. Biotechnol. 65, 473-478.

El-Gendy, S. M., Marth, E. H., 1981. Growth of aflatoxin production by Aspergillus parasiticus in the presence of Lactobacillus casei. J. Food Prot. 44, 211-212.

El-Nagerabi, S. A. F., El-shafie, A. E., Alkhanjari, S. S., Al-Bahry, S. N., Elamin, M. R., 2013. The potential of Baobab (Adansonia digitata L.) extracts as biocontrol on the growth and aflatoxin production by Aspergillus flavus and A. parasiticus. J. Food Res. 2(3), 93-103.

Enyiukwu, D. N., Awurum, A. N., Nwaneri, J. A., 2014. Mycotoxins in stored agricultural products: Implications to food safety and health and prospects of plant-derived pesticides as novel approach to their management. Green. J. Microbiol. Antimicrob. 2(3), 32-48.

Ephrem, G., 2015. Aflatoxin contamination in groundnut (Arachis hypogaea L.) caused by Aspergillus species in Ethiopia. J. Appl. Environ. Microbiol. 3(1), 11-19.

European Commission-EC, 2010. Commission regulation (EU) no 165/2010 of 26 February 2010, amending regulation (EC) no 1881/2006 setting maximum levels for certain contaminants in foodstuffs as regards aflatoxin. Official J. Europ. Union, pp.8-12.

Eva, G., Ernesto, M., Susana, P., 2011. Aflatoxins and Their Impact on Human and Animal Health: An Emerging Problem, Aflatoxins Biochemistry and Molecular Biology, Dr. Ramon G. Guevara-Gonzalez (Eds.).

Ezekiel, C. N., Alabi, O. A., Anokwuru, C. P., Oginni, O., 2011. Studies on dietary aflatoxin-induced genotoxicity using two in vivo bioassays. Arch. Appl. Sci. Res. 3(2), 97-106.

Ezekiel, C. N., Kolawole, A., Jane, M., Yinka, S., Ihuoma, E., Oluwawapelumi, A. O., Wilfred, A., Michael, S., Gordon, S., Rudolf, K., 2018. Traditionally processed beverages in Africa: A review of the mycotoxin occurrence patterns and exposure assessment. Comp. Rev. Food Sci. Food Saf. 17, 334-351.

Fakruddin, Md., Abhijit, C., Hossain, M. N., Monzur, M. A., 2018. Characterization of aflatoxin producing Aspergillus flavus from food and feed samples. Springer Plus. 4, 159.

Fan, S., Zhang, F., Liu, S., Yu, C., Guan, D., Pan, C., 2013. Removal of aflatoxin biin edible plant oils by oscillating treatment with alkaline electrolyzed water. Food Chem. 141, 3118-3123.

Fapohunda, S., Ezekiel, C. N., Alabi, O., Omole, A., Chioma, S., 2008. Aflatoxin-mediated sperm and blood cell abnormalities in mice fed with contaminated corn. Mycobiology. 36(4), 255-259.

Giovati, L., Magliani, W., Ciociola, T., Santinoli, C., Conti, S., Polonelli, L., 2015. AFM1 in milk: physical, biological, and prophylactic methods to mitigate contamination. Toxins. $7,4330^{-}$ 4349.

Gong, Y. Y., Turner, P. C., Hall, A. J., Wild, C. P., 2008. Aflatoxin exposure and impaired child growth in West Africa: An unexplored international public health burden? In: Mycotoxins Detection Methods, Management and Public Health and Agricultural Trade (Eds.: Leslie, J. F., Banerjee, R., Visconti, A.), pp.53-66.

Gong, Y. Y., Wilson, S., Mwatha, J. K., 2012. Aflatoxin exposure may contribute to chronic hepatomegaly in Kenyan school children. Environ. Health Perspect. 120, 893-896.

Gourama, H., Bullerman L. B., 1997. Antiaflatoxigenic activity of Lactobacillus casei subsp. pseudoplantarum. Int. J. Food 
Microbiol. 34, 131-143.

Gowda, N., Swamy, H., Mahajan, P., 2013. Recent advances for control, counteraction and amelioration of potential aflatoxins in animal feeds. InTech. 1, 130-140.

Groopman, J. D., Egner, P. A., Schulze, K. J., 2014. Aflatoxin exposure during the first 1000 days of life in rural South Asia assessed by aflatoxin B1lysine albumin biomarkers. Food Chem. Toxicol. 74, 184-189.

Hamed, K. A., Robert, M. Z., Arnold, B. H., Craig, A., 2006. Biocontrol of aflatoxin in corn by inoculation with non-aflatoxigenic Aspergillus flavus isolates. Biocontrol Sci. Technol. 16(5), 437-449.

Hernandez-Vargas, H., Castelino, J., Silver, M. J., 2015. Exposure to aflatoxin $\mathrm{B} 1$ in utero is associated with DNA methylation in white blood cells of infants in The Gambia. Int. J. Epidemiol. $44,1238-1248$.

Herzallah, S., Alshawabkeh, K., Fataftah, A. A., 2008. Aflatoxin decontamination of artificially contaminated feeds by sunlight, radiation, and micro wave heating. J. Appl. Poult. Res. 17, 515521.

Hussain, A., Shafqatullah, J., Ali, Z., 2012. Inhibition of aflatoxin producing fungus using chemical, herbal compounds/spices and plants. Pure Appl. Biol. 1(1), 8-13.

Inan, F., Pala, M., Doymaz, I., 2007. Use of ozone in detoxification of aflatoxin $\mathrm{B} 1$ in red pepper. $\mathrm{J}$. Stored Prod. Res. 43, 425-429.

Ines, J., Carlos, S., Amani, L., Patricia, M., Teresa, GJ., Salem, S., 2018. Mycoflora isolation and molecular characterization of Aspergillus and Fusarium species in Tunisian cereals. Saudi J. Biol. Sci. 25, 868-874.

Jaynes, W., Zartman, R., 2011. Aflatoxin toxicity reduction in feed by enhanced binding to surface modified clay additives. Toxins. 3(6), 551-565.

Jef, L., Jia-Sheng, W., Kelly, J., 2015. Serum aflatoxin B1-lysine adducts level in adult women from Eastern Province in Kenya depends on household socio-economic status: A cross sectional study. Soc. Sci. Med. J. 146, 104-110.

Jiang, Yi., Pauline, E. J., Peter, P., Jia-Sheng, W., William, O. E., Timothy, D. P., Jonathan, H. W., 2008. Aflatoxin-related immune dysfunction in health and in human immuno deficiency virus disease. Clin. Devel. Immunol. 1, 1-12.

Juan, C., Ritieni, A., Manes, J., 2012. Determination of trichothecenes and zearalenones in grain cereal, flour and bread by liquid chromatography tandem mass spectroscopy. Food Chem. 134(4), 2389-2397.

Kabak, B., Dobson, A. D., Ișl Var, 2006. Strategies to prevent mycotoxin contamination of food and animal feed. Crit. Rev. Food Sci. Nutr. 1, 593618.

Kabak, B., Dobson, A. D., 2009. Biological strategies to counteract the effects of mycotoxins. Food Prot. 72(9), 2006-2016.

Karaca, H., Velioglu, Y. S., 2014. Effects of ozone treatments on microbial quality and some chemical properties of lettuce, spinach, and parsley. Postharv. Biol. Technol. 88, 46-53.

Kehinde, M. T., Oluwafem, F., Itoandon, E. E., Orji, F. A., Ajayi, O. I., 2014. Fungal profile and aflatoxin contamination in poultry feeds sold in Abeokuta, Ogun State, Nigeria. Official J. Niger. Inst. Food Sci. Technol. 32(1), 73-79.

Kendra, D. F., Dyer, R. B., 2007. Opportunities for biotechnology and policy regarding mycotoxin issues in international trade. Int. J. Food Microbiol. 119(1-2), 147-151.

Khan, F. A., Zahoor, M., 2014. In vivo detoxification of aflatoxin $\mathrm{B} 1$ by magnetic carbon nanostructures prepared from bagasse. BMC Vet. Res. 10, 255.

Kiran, L., Kasturi, K., Sambasiva, R., 2014. Aflatoxins in food and feed: The science of safe food. Research \& Reviews. J. Food Sci. Technol. 3(2), 6-11.

Kiran, L., Kasturi, K., Sambasiva, R. K., 2014. Aflatoxins in food and feed: The science of safe food. Research \& Reviews. J. Food Sci. Technol. 3(2), 6-11.

Köhl, J., Postma, J., Nicot, P., Ruocco, M., Blum, B., 2011. Stepwise screening of microorganisms for commercial use in biological control of plant-pathogenic fungi and bacteria. Biol. Control. 57, 1-12.

Magoha, H., Kimanya, M., De Meulenaer, B., Roberfroid, D., Lachat, C., Kolsteren, P., 2014. Association between aflatoxin M1 exposure through breast milk and growth impairment in infants from Northern Tanzania. World Mycotoxin J. 7, 277-284.

Matome, G., Hunja, M., Akebe, L. K., Michael, P., 2017. Morphological characterization and determination of aflatoxin-production potentials of Aspergillus flavus isolated from maize and soil in Kenya. Agriculture. 7, 80-94. 
Matthias, D., 2009. Distribution and molecular characterization of aflatoxin-producing and nonproducing isolates of Aspergillus section flavi for biological control of aflatoxin contamination in maize in Nigeria. Institut für Nutzpflanzenwissenschaften und Ressourc enschutz (INRES), doctoral Dissertation paper pp.1-91.

Merrill, M.L., Bohnert, D. W., Harmon, D. L., Craig, A. M., Schrick, F. N., 2007. The ability of a yeast-derived cell wall preparation to minimize the toxic effects of high-ergot alkaloid tall fescue straw in beef cattle. J. Anim. Sci. 85, 2596-2605.

Mohamed, A., Aminata, O., 2016. Toxicology, biosynthesis, bio-control of aflatoxin and new methods of detection. Asian Pac. J. Trop. Biomed. 6(9), 808-814.

Navya, H., Naveen, J., Hariprasad, P., Niranjana, S., 2017. Characterization of nonaflatoxigenic strains of Aspergillus flavus as potential biocontrol agent for the management of aflatoxin contamination in groundnut. Microb. Pathogen. 102, 21-28.

Osweiler, G. D., 2000. Mycotoxins: contemporary issues of food animal health and productivity. Vet. Clin. North Am. Food Anim. Pract. 16, 511530.

Park, B. J., Takatori, K., Sugita-Konishi, Y., Kim, I. H., Lee, M. H., Han, D. W., 2007. Degradation of mycotoxins using microwave-induced argon plasma at atmospheric pressure. Surface Coating Technol. 201, 5733-5737.

Patchimaporn, U., Alexander, N., Marcus, N., Joachim, M., Bernard, V., Ranajit, B., 2017. Innovative technologies to manage aflatoxins in foods and feeds and the profitability of application. Food Control. 76, 127-138.

Pooja, B. M., Sowmini, S., Madhurima, B. P., Farid, W., Kiran, K. S., 2015. Biotechnological advances for combating Aspergillus flavus and aflatoxin contamination in crops. Plant Sci. 234, 119-132.

Pradeep, A. G., Lokesh, S., Ravi, V. R., 2003. Efficacy of some essential oils on seed mycoflora and seedling quality of some crop species saved by farmers. Adv. Plant Sci. 16, 53-58.

Prasad, K., Bhatnagar-Mathur, P., Narasu, M. L., Waliyar, F., Sharma, K. K., 2012. Transgenic approaches for improving fungal disease resistance in groundnut. Technol. Spectr. 5, 54-63.

Prietto, L., Moraes, P. S., Kraus, R. B., Meneghetti,
V., Fagundes, C. A., Furlong, E. B., 2015. Postharvest operations and aflatoxin levels in rice (Oryza sativa). Crop Prot. 78, 172-177.

Probst, C., Bandyopadhyay, R., Price L. E., Cotty, P. J., 2011. Identification of atoxigenic Aspergillus flavus isolates to reduce aflatoxin contamination of maize in Kenya. Plant Dis. 95, 212-218.

Rajasekaran, K., De Lucca, A. J., Cary, J. W., 2009. Aflatoxin control through transgenic approaches. Toxin Rev. 28, 89-101.

Rashad, R., Al-Hindi, Soher, E. A., Amal, S. H., Mona, G. A., Saad Al-Masaudi, Soad, K., AlJaouni, Steve, M. H., 2018. Isolation and molecular characterization of mycotoxigenic fungi in agar wood. Saudi J. Biol. Sci. 25, 17811787.

Reddy, V. K., Srinivas, M., Reddy, A. R., Srujana, G., Surenkha, Reddy, S. M., 2011. Plant extracts in the management of aflatoxin production by Aspergillus flavus. Int. J. Pharmaceut. Biol. Sci. 2(2), 492-498.

Routledge, M. N., Gong, Y. Y., 2011. Developing biomarkers of human exposure to mycotoxins: In: Determining Mycotoxins and Mycotoxigenic Fungi in Food and Feed, Wood Head Publishing, Cambridge, UK, pp.225-244.

Sardiñas, N., Gil-Serna, J., Santos, L., Ramos, A. J., González, M. T., Patiño, B., Vázquez, C., 2011. Detection of potentially mycotoxigenic Aspergillus species in Capsicum powder by a highly sensitive PCR-based detection method. Food Control. 22(8), 1363-1366.

Schleicher, R. L., McCoy, L. F., Powers, C. D., Sternberg, M. R., Pfeiffer, C. M., 2013. Serum concentrations of an aflatoxin-albumin adduct in the National Health and Nutrition Examination Survey 1999-2000. Clin. Chim. Acta. 423, 46-50.

Shuaib, F. M., Jolly, P. E., Ehiri, J. E., 2010. Association between birth outcomes and aflatoxin B1 biomarker blood levels in pregnant women in Kumasi, Ghana. Trop. Med. Int. Health. 15, 160-167.

Soad, K., Al-Jaouni, Steve, M. H., 2018. Isolation and molecular characterization of mycotoxigenic fungi in agar wood. Saudi J. Biol. Sci. $25,1781-1787$.

Sudakin, D. L., 2003. Dietary aflatoxin exposure and chemoprevention of cancer: A clinical review. J. Toxicol. Clin. Toxicol. 41, 195-204.

Suzuki, I., Nomuraand, M., Morachi, T., 1991. 
Isolation of lactic acid bacteria which suppress mold growth and show antifungal action. Milchwissens Chaft. 70, 635-639.

Tagne, A., Feujio, T. P., Sonna, C., 2008. Essential oils and plant extracts as potential substitutes to synthetic fungicides in the control of fungi. Endure International Conference, Diversifying Crop Protection, France, October 12-15, pp.1-3.

Temesgen, A., Teshome, G., 2018. Major mycotoxins occurrence, prevention and control approaches. Biotechnol. Mol. Biol. Rev. 12(1), 1-11.

Thana Boripat, D., 2011. Control of aflatoxins in agricultural products using plant extracts. KMITL Sci. Tech. J. 11(1), 35-42.

Thrasher, J. D., Crawley, S. L., 2009. The biocontaminants and complexity of damp indoor spacs: More than meets the eyes. Toxicol. Indust. Health. 25, 583-616.

Tiwari, B., Brennan, C. S., Curran, T., Gallagher, E., Cullen, P., O'Donnell, C., 2010. Application of ozone in grain processing. J. Cereal Sci. 51, 248255.

Turner, P. C., Moore, S. E., Hall, A. J., Prentice, A. M., Wild, C. P., 2003. Modification of immune function through exposure to dietary aflatoxin in Gambian children. Environ. Health Perspect. 111, 217-220.

UNICEF, 2012. WHO, World Bank Levels and trends in child malnutrition: Joint child malnutrition estimates. New York, NY: United Nations International Children's Fund; Geneva: World Health Organization; Washington DC.

Villar, S., Le Roux-Goglin, E., Gouas, D. A., 2011. Seasonal variation in TP53 R249 S-mutated serum DNA with aflatoxin exposure and hepatitis B virus infection. Environ. Health Perspect. 119, 1635-1640.

Wafaa, H., El-Habbasha, E. F., Medhat, M., 2014. Potential biocontrol agents used for management of aflatoxin contamination in corn grain crop. Res. J. Pharmaceut. Biol. Chem. Sci. 5(5), 521-527.

Waliyar, F., Osiru, M., Sudini, H, Njoroge, S., 2013. Reducing aflatoxins in ground nuts through integrated management and biocontrol. In:
Aflatoxins-finding solutions for improved food safety. Int. Food Policy Res. Inst. 1, 1-2.

Wallace, D. C., 1997. Mitochondrial DNA in aging and disease. Scient. Amer. 1, 40-47.

WHO, 2008. World Health Statistics: World Health Organization, Geneva, Retrieved from, http://www.who.int/whosis/whostat/EN_WHS 08_Full.pdf.

$\mathrm{Wu}, \mathrm{F}$., 2006. Mycotoxin reduction in Bt corn: Potential economic, health, and regulatory impacts. ISB News report, September 2006.

Wu, H. C., Wang, Q., Yang, H. I., 2009. Aflatoxin B1 exposure, hepatitis B virus infection, and hepatocellular carcinoma in Taiwan. Cancer Epidemiol. Biomark. Prev. 18, 846-853.

Wu, Y. Z., Lu, F. P., Jiang, H. L., Tan, C. P., Yao, D. S., Xie, C. F., 2015. The furofuran-ring selectivity, hydrogen peroxide production and low $\mathrm{Km}$ value are the three elements for highly effective detoxification of aflatoxin oxidase. Food Chem. Toxicol. 76, 125-131.

Yu, J., Cleveland, T. E., Nierman, W. C., Bennett, J. W., 2005. Aspergillus flavus genomics: gateway to human and animal health, food safety and crop resistance to diseases. Rev. Iberoamer. Micol. 22, 194-202.

Yun, G., Sinead, W., Michae, N. R., 2016. Aflatoxin exposure and associated human health effects, a review of epidemiological studies. Food Saf. 4, 14-27.

Zanon, A., Chiotta, M., Giaj-Merlera, G., Barros, G., 2013. Evaluation of potential biocontrol agent for aflatoxin in Argentinean peanuts. Int. J. Food Microbiol. 162, 220-225.

Zeinvand-Lorestani, H., Sabzevari, O., Setayesh, N., Amini, M., Nili-Ahmadabadi, Faramarzi, M. A., 2015. Comparative study of in vitro prooxidative properties and genotoxicity induced by aflatoxin B1 and its laccase-mediated detoxification products. Chemosphere. 135, 1-6.

Zsolt, P., Eszter, D., Anita, L., Balázs, K., József, K., Endre, N., 2017. Biological degradation of aflatoxin B1by a Rhodococcus pyridinivorans strain in by-product of bio-ethanol. Anim. Feed Sci. Technol. 224, 104-114.

\section{How to cite this article:}

Temesgen, A. G., Teshome, G. B., Biniam, M. E., Awoke, Y. D., 2020. Health impacts of aflatoxin and control of aflatoxigenic fungi. Int. J. Curr. Res. Biosci. Plant Biol. 7(3), 39-54.

doi: https://doi.org/10.20546/ijcrbp.2020.703.004 